\title{
Sex disparity in cancer: roles of microRNAs and related functional players
}

\author{
Alessandra Carè $^{1}$ Maria Bellenghi ${ }^{1} \cdot$ Paola Matarrese $^{1} \cdot$ Lucia Gabriele $^{2} \cdot$ Stefano Salvioli $^{3} \cdot$ Walter Malorni $^{1}{ }^{1}$
}

Received: 3 July 2017 / Revised: 13 November 2017 / Accepted: 24 November 2017 / Published online: 19 January 2018

(c) The Author(s) 2018. This article is published with open access

\begin{abstract}
A sexual dimorphism at the cellular level has been suggested to play a role in cancer onset and progression. In particular, very recent studies have unraveled striking differences between cells carrying XX or XY chromosomes in terms of response to stressful stimuli, indicating the presence of genetic and epigenetic differences determining sex-specific metabolic or phenotypic traits. Although this field of investigation is still in its infancy, available data suggest a key role of sexual chromosomes in determining cell life or death. In particular, cells carrying XX chromosomes exhibit a higher adaptive potential and survival behavior in response to microenvironmental variations with respect to XY cells. Cells from females also appear to be equipped with more efficient epigenetic machinery than the male counterpart. In particular, the $\mathrm{X}$ chromosome contains an unexpected high number of microRNAs (miRs), at present 118, in comparison with only two miRs localized on chromosome $\mathrm{Y}$, and an average of $40-50$ on the autosomes. The regulatory power of these small non-coding RNAs is well recognized, as 30-50\% of all protein-coding genes are targeted by miRs and their role in cell fate has been well demonstrated. In addition, several further insights, including DNA methylation patterns that are different in males and females, claim for a significant gender disparity in cancer and in the immune system activity against tumors. In this brief paper, we analyze the state of the art of our knowledge on the implication of miRs encoded on sex chromosomes, and their related functional paths, in the regulation of cell homeostasis and depict possible perspectives for the epigenetic research in the field.
\end{abstract}

\section{Introduction}

Growing amounts of evidence are showing the influence of sex (i.e., biological determinants) and/or gender (that includes socio-cultural matter) on pathological conditions and clinical outcomes [1,2]. Differences have been detected in a number of either transmissible or non-transmissible diseases. In particular, epidemiology clearly suggests that, apart from reproductive organs, several forms of cancers of

Walter Malorni

malorni@iss.it

1 Oncology Unit, Center for Gender-specific Medicine Istituto Superiore di Sanita', Viale Regina Elena, 29900161 Rome, Italy

2 Immunotherapy Unit, Department of Oncology and Molecular Medicine, Istituto Superiore di Sanita', Viale Regina Elena, 299 00161 Rome, Italy

3 Department of Experimental, Diagnostic and Specialty Medicine (DIMES), University of Bologna, Via San Giacomo 12, 40126 Bologna, Italy great relevance, e.g., melanoma or leukemias, clearly display a gender disparity in terms of incidence, prevalence, or response to therapy [3]. Although a general female advantage has been observed by these epidemiological studies, few data have emerged so far explaining this trend [4]. Recent results also suggest that sex-specific differences could take place in cell death programs, representing critical features for the identification of sex-specific chemotherapeutic targets [5]. As a general rule, cells from males and females (here called male cells, $\mathrm{XY}$, and female cells, $\mathrm{XX}$ ) respond differently to injuries possibly because of their different capability to face cellular stress [6]. In particular, the same stressor can preferentially induce apoptosis in male cells, and survival by induction of autophagy in female cells. Of notice, these results come from studies carried out with non-transformed cells, essentially vessel cells (such as vascular smooth muscle cells or endothelial cells and fibroblasts) [7-9]. This difference is probably due to the greater capacity of the XX cells to prevent and repair the damage than $\mathrm{XY}$ ones [8]. In addition, $\mathrm{XY}$ and $\mathrm{XX}$ cells are differently susceptible to various cytotoxic agents. For 
instance, $\mathrm{XY}$ neurons were reported to be more sensitive to excitotoxicity than $\mathrm{XX}$ neurons, which appeared more prone to staurosporine-induced apoptosis [9]. These gender differences in cell susceptibility to an exogenous stress, that could be applied to non-cancer cells of different histotype, seem to be related to the inability of XY cells to maintain intracellular levels of reduced glutathione, paralleled by an increased activity of Superoxide Dismutase (SOD) and catalase activity in XX cells as observed either in vitro or in in vivo studies [2, 6-13]. Both genetic and hormonal differences have been hypothesized to be at the basis of all these disparities contributing to sex-specific phenotypes [14].

\section{Discussion of literature data}

\section{The genetic issue}

Many observations on the differences between $\mathrm{XX}$ and $\mathrm{XY}$ cells are derived from studies carried out with in vitro models. This suggests that at least part of the observed disparities are independent from the effects of sexual hormones and could be directly imputable to genetic differences, including $\mathrm{X}$ and $\mathrm{Y}$ sex chromosomes. However, the study of the roles of these chromosomes in the maintenance of cell homeostasis and death is still at the beginning. One key point deals with the presence of the two $\mathrm{X}$ chromosomes in cells from females and one $\mathrm{X}$ chromosome in cells from males. As a general rule, the phenomenon of $\mathrm{X}$ inactivation should theoretically re-equilibrate female and male gene expression. However, this is not always the case, as up to $15 \%$ of $\mathrm{X}$-linked genes escape $\mathrm{X}$-chromosome inactivation (XCI) leading, in females, to the presence of a second, functional copy of the genes located in the XCIescaped regions [15, 16]. A systematic analysis of these genes has not been performed, due to the extremely heterogeneous scenario of XCI (escaper genes may display different levels of expression between tissues and subjects [17]), thus making it difficult to understand which role, if any, these escaper genes may play in cell-sex disparity. However, Dunford and coauthors recently reported that, among escaper genes, there are tumor suppressors (ATRX, CNKSR2, DDX3X, KDM5C, KDM6A, and MAGEC3) which, when mutated, are significantly associated with cancer in males [18]. On this basis, it has been suggested that the presence of a second functional copy of a gene in an XCI-escaper region could protect females from the negative effects of the mutated copy [18]. In few words, the presence of two X chromosomes, i.e., different alleles of the same gene, could provide a significant advantage to cells from females since they could counteract gene mutations leading to cancer [19]. However, it is possible that this sort of "XCI- mediated protection" does not last for the whole life. Actually, it is reported that from middle age (around 55 years) onward, a phenomenon of age-related preferential inactivation of one $X$ chromosome takes place [20-23]. This XCI skewing can lead to the expression of deleterious alleles and thus to an increased risk of morbidity. Actually, women that are offsprings of long-lived parents have a lower XCI skewing and lower prevalence of several diseases such as cardiovascular, skeletal, respiratory, neurologic diseases, and cancer with respect to the age-matched counterparts that were born from non-long-lived parents [24]. The reasons for this XCI skewing toward the chromosome containing the deleterious alleles are not known. However, this phenomenon has been observed since 1995 for many diseases including cancer [25-30].

On the other side, the presence in women of a number of non-inactivated $\mathrm{X}$-linked alleles is associated not only to the protection against diseases but also to some immunological disorders, including autoimmune diseases [31]. This phenomenon is likely accounted by the fact that many XCIescaper genes are involved in immune response. This issue will be further discussed later.

\section{The epigenetic issue}

Besides the genetic determinants mentioned above, a number of epigenetic factors, including microRNAs (miRs), have been hypothesized to play a role in cancer onset and progression. MiRs are in fact emerging as critical factors in post-transcriptional regulation of gene expression by influencing the main cellular activities, including cell proliferation and dissemination capabilities as well as cell death. These short non-coding RNAs (21-25 nucleotides) negatively modulate their target mRNAs by direct binding to the 3 untranslated regions (UTRs) with consequent translational repression or mRNA degradation, depending on sequence complementarity [32]. Notably, $\mathrm{X}$ chromosome contains an unexpected high number of miRs, at present 118, in comparison with only 2 miRs localized on chromosome $\mathrm{Y}$, and an average of 40-50 on the autosomes [33]. The regulatory power of these small non-coding RNAs is well recognized, as $30-50 \%$ of all protein-coding genes are targeted by miRs according to complex interconnected circuitries as each gene might be regulated by many miRs and each single miR has up to hundreds of direct targets.

The role of miRs in cancer has been deeply analyzed demonstrating their tumorigenic as well as tumorsuppressor functions. As concerns sex chromosomes, it is important to highlight that the X-chromosome not only displays a high density of miRs, but also that several of them are involved in immunity regulation [34]. Moreover, the contemporary presence, on this chromosome, of genes coding for proteins playing immunological roles together 
with a number of miRs impacting on immune system integrity and function may suggest the existence of sexrelated loops functional to immunosurveillance (or failure of immunosurveillance) against tumor onset and progression [33]. Since the development of immunotherapeutic approaches recently gained the attention of physicians in the fight against cancer, the scenario depicted above appears to be of great interest. In particular, inhibitors of different immune checkpoints have been introduced for the treatment of different, otherwise non-responsive, tumors as well as, more recently, for first line treatment. This strategy stems from the ability of cancer cells to escape the surveillance normally exerted by the immune system via a series of key molecules, e.g., cytotoxic T-lymphocyte antigen-4 (CTLA4) or programmed cell death protein 1 (PD-1), capable of inhibiting immune cells $[35,36]$. In particular, PD-L1 and PD-L2 are transmembrane proteins that, by binding to their receptor PD-1, activate the PD-1/PD-L1 or PD-L2 pathway and induce T-cells to undergo apoptosis suppressing their activation. Hence, the immunosurveillance against tumors is hindered and tumor progression can take place [36].

Finally, it is important to mention that further possible epigenetic mechanisms could give rise to sex disparities. In particular, it has been observed that DNA methylation pattern of autosomes is different between males and females $[37,38]$. In the first study [37], carried out in saliva samples, 580 autosomal sites showing strong differences between males and females have been detected. In the second study [38], performed on three independent cohorts of European subjects, $1184 \mathrm{CpG}$ sites with different methylation levels between sexes were identified in blood cells. The same study also showed that two genes, CISH and RAB23, displayed a significant association between DNA methylation and expression in men and women. These two genes are involved in Hedgehog pathway [39] and inhibition of the JAK-STAT pathway [40]. Hedgehog pathway is crucial for response to injury, tissue stress, healing, and regeneration, whereas JAK-STAT pathway is fundamental for regulatory T-cell function [40]. Therefore, a sex-specific epigenetic control over these two pathways may in part account for the observed differences between men and women in immune and autoimmune responses [41].

\section{Sex and immunity}

A significant difference between the male and female immune system function has recently been described. As reviewed by Klein and Flanagan, the female immune system appears more efficient in a number of species, including humans [41]. Importantly, this different efficiency is present all along the entire human lifespan. From childhood to old age, the female immune system appears more powerful and able to better counteract infectious and non-infectious diseases, including cancer [41]. This fact may be related to the different evolution of the two sexes in relation to their different and complementary biological functions. It means that, independent from the hormone-related functions, immunity is per se sex-biased, i.e., it could depend upon genetic or epigenetic matters. In addition, in females, this advantage can also become detrimental since the sex-biased nature of the immune system function can result in autoimmune diseases [31, 41, 42]. In this scenario, a role of sex has also been linked to PD-1 modulation [43, 44]. In patients with melanoma, the inhibition of PD-1/PD-L1 interaction resulted significantly associated with sex as the median objective response rate (ORR) was $54.6 \%$ among men and just $33.1 \%$ among women, and median progression-free survival (PFS) was 18 months vs. 5.5 months, respectively $[43,45]$. The underlying reasons are not known, but they possibly involve the immune system sex disparity obviously based on sex hormones and other factors differently expressed in women and also on genetic, e.g., sex chromosomal-associated issues, and epigenetic signals, such as miRs.

\section{Sex chromosomes and miRs}

Based on the above findings, an miR-dependent regulation of molecules of relevance in modern immunotherapy such as PD-L1 should merit particular attention. Indeed, PD-L1 expression appears to be directly or indirectly controlled by several X-linked miRs (Fig. 1 and Table 1). According to TargetScan 7.1 (www. targetscan.org), miR-106b, miR-20b, and miR-513, all three localized on chromosome $\mathrm{X}$, are putative repressors of PD-L1 by direct binding to their 3'UTRs. Specifically, miR-106b and miR-20b, which are part of the miR-106-363 cluster, including miR-106a, 18b, 20b, 19b2, 92a2, and miR-363, were reported to play an oncogenic role in different tumors [46]. Furthermore, miR106a was reported to downregulate the antiinflammatory cytokine IL-10 [47] and the whole cluster was suggested to play a role in both innate and adaptive immunity [48]. Interestingly, miR-106b and miR-20a, together with miR-221, were proposed as biomarkers for early detection of gastric cancer [46]. Other miRs, such as miR-513 and miR-514, members of the X-linked primatespecific miR-506-514 cluster, have been associated with cancer, particularly with melanocyte transformation, melanoma promotion, and sensitivity to BRAF inhibitors [49, 50]. In addition, in biliary epithelial cells, miR-513 is downregulated by interferon- $\gamma$ (IFN- $\gamma$ ) and regulates PDL1 translation by direct targeting, thus suggesting an miRmediated gene regulation of responses to IFN- $\gamma$ [51].

PD-L1 transcription is induced by hypoxia-inducible factor- $1 \alpha(\mathrm{HIF} \alpha)$ and signal transducer and activation of transcription-3 (STAT3) factors, directly acting on its 

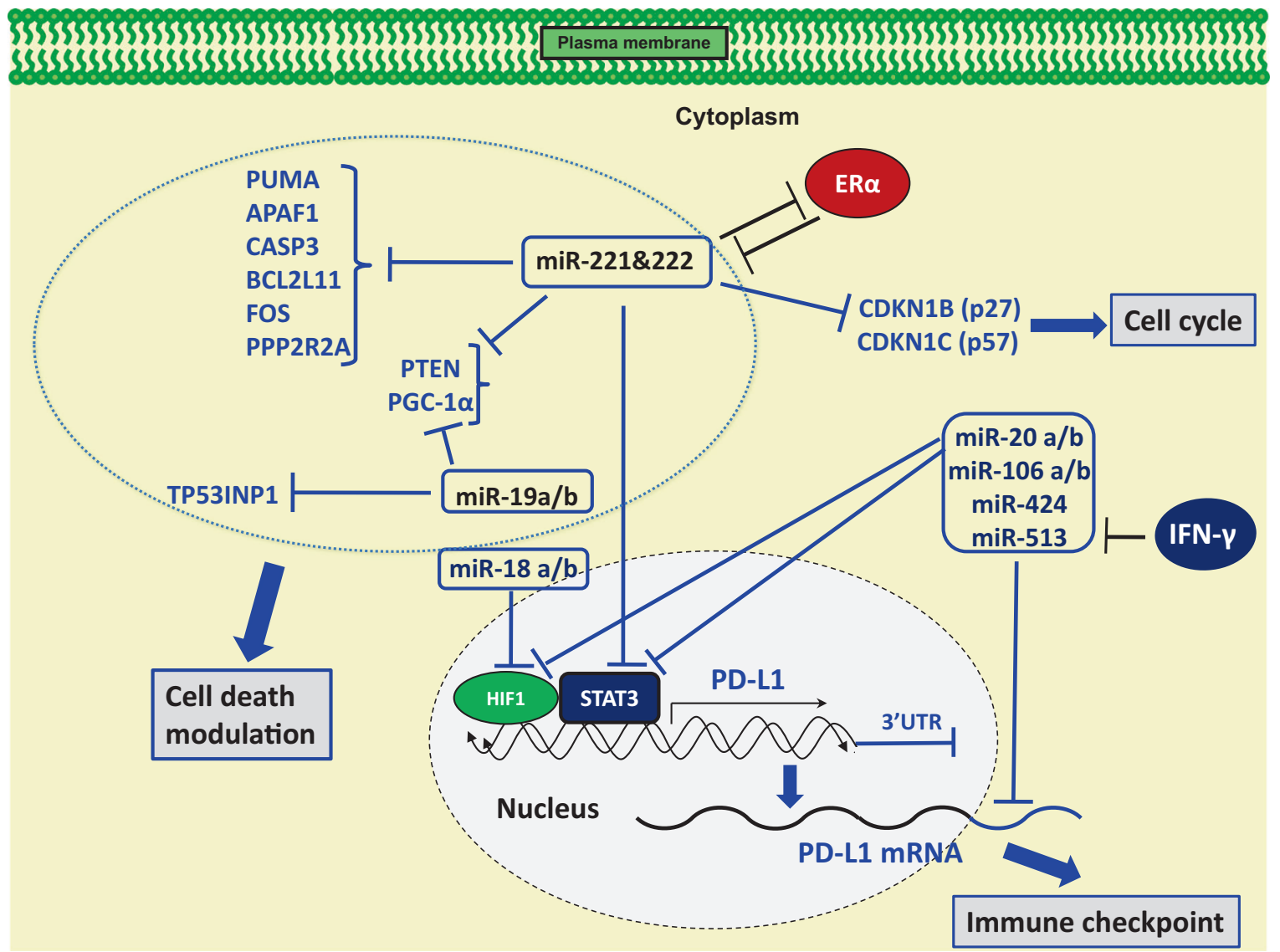

Fig. $1 \mathrm{X}$-linked microRNAs regulating cancer cell homeostasis. Schematic representation of miR-based, direct or indirect, regulation of PD-L1, as an example of immune checkpoint key molecule. Additional relevant genes targeted by the indicated miRs and involved in cell cycle and cell death modulation are also shown. See text for details. PD-L1 programmed cell death protein ligand, HIF1 $\alpha$ hypoxiainducible factor- $1 \alpha$, STAT3 signal transducer and activation of transcription-3, ER $\alpha$ estrogen receptor $\alpha$, IFN $\gamma$ interferon $\gamma$, PTEN

promoter [52]. These transcription factors are regulated by miR-221\&222 and by miR-18 and miR-19, the former couple specifically localized on chromosome $\mathrm{X}$ and the latter encoded on both chromosome 13 and chromosome X. As also $\mathrm{miR}-20 \mathrm{a} / \mathrm{b}$ and $\mathrm{miR}-106 \mathrm{a} / \mathrm{b}$ are produced from different miR gene clusters, apparently derived from genetic duplications, it is important to discriminate the contribution of X-chromosome-encoded miRs, looking for their possible role as functional modulators of female immunity [53, 54]. Both miR-18 and -19 are able to potentiate the nuclear factor- $\mathrm{\kappa B}(\mathrm{NF}-\mathrm{\kappa B})$ activity, in turn favoring inflammation $[53,55]$. Likewise, miR-20b appears to target both HIF-1a and STAT3 transcription factors [56], thus repressing PD$\mathrm{L} 1$, either by direct pairing to its $3^{\prime} \mathrm{UTR}$ or indirectly through the downregulation of these two activating transcription factors. It is important to point out that, according to Targetscan, miR-20 and miR-106 are putative controllers phosphatase and tensin homolog, PUMA p53 upregulated modulator of apoptosis, APAF1 apoptotic protease activating factor-1, CASP3 caspase 3, BCL2L11 BCL2-like11, PPP2R2A protein phosphatase 2, regulatory subunit $\mathrm{b}, \alpha$, TP53INP1 tumor protein $\mathrm{p} 53$-inducible nuclear protein $1, \mathrm{PGC}-1 \alpha$ peroxisome proliferator-activated receptorgamma coactivator 1-alpha, CDKN1B -p27kip1 cyclin-dependent kinase inhibitor 1b, CDKN1C-p57kip2 cyclin-dependent kinase inhibitor $1 \mathrm{c}$

also of PD-L2, in agreement with its predominant posttranscriptional regulation. Finally, another X-linked miR, miR-424, directly targets either PD-L1 or CD80, thus possibly regulating both the PD-L1/PD-1 and CD80/CTLA-4 pathways further supporting the option of X-linked disparities associated with immune checkpoint responses [57].

How these $\mathrm{X}$-linked miRs could provide a protection to female cells but not to male ones is still a matter of debate. A possibility that has been envisaged some years ago is that some of these $\mathrm{X}$-linked miRs lie in the chromosomal regions that escape XCI and therefore are expressed at higher levels in female cells [33]. A precise map of XCIescaper miRs is still missing and this should be the objective of specific research. However, it has been observed that in patients with active lupus $18, \mathrm{X}$-linked miRs are more expressed in CD4+ T-cells from women with respect to men, and five of them are regulated by demethylation [31]. 
This could suggest that these five miRs are XCI escapers, or, alternatively, that they could be demethylated by an XCI-escaper gene.

Among the X-linked miRs, miR-221\&222 are the most extensively studied in tumors of different origins where they act as oncomirs controlling the development and progression of the tumor through the down-modulation of several key targets [58]. However, their possible impact on sex differences detected in tumor incidence and progression is still neglected. Literature on this argument appears to be focused on the study of the impact of hormones on cancer. For instance, it has been suggested that melanoma could be classified among the hormone-sensitive tumors according to complex, overlapping actions played by estrogens and androgens, particularly by the opposite effects of $\alpha$ and $\beta$ estrogen receptors (ER) [59]. In particular, ER $\beta$ has been reported as capable of inducing autophagy-mediated cell death both in post-mitotic cells and proliferating cells, whereas $\mathrm{ER} \alpha$ has been suggested to induce proliferation in transformed cells and autophagy in post-mitotic cells [60, 61]. Interestingly, among the number of X-linked miRs, six of them putatively bind and regulate $\mathrm{ER} \alpha$, including miR221\&222 [62]. Specifically, miR-221\&222 inhibit ER $\alpha$ mRNA translation by direct binding to its 3UTR, being in turn repressed by $\mathrm{ER} \alpha$ according to a negative feedback loop [63].

Conversely, some insights are derived from studies carried out on miR-221\&222 in cardiac cells. In fact, these two miRs display lower expression levels in females with respect to male murine cardiomyocytes contributing to sex-dimorphic cardiac phenotypes [64]. The mechanism underlying this disparity appears to involve endothelial nitric oxide synthase (eNOS) modulation via the unblocked expression of miR$221 \& 222$ direct target Ets-1 [65]. These data could be of relevance in view of the different cardiotoxicity of cancer chemotherapy in males and females [66].

\section{Programmed cell death and miRs}

Once again, cells from males and females seem to act differently when headed for death if subjected to the same exogenous stress, as female non-tumor cells are more prone to the autophagic protective effects, whereas male cells more frequently undergo apoptosis and/or necrosis $[7,8,11$, 12, 67, 68]. Looking for factors underlying this disparity, one option to consider is the involvement of the $\mathrm{X}$ chromosome-linked inhibitor of apoptosis (XIAP) whose reduction can promote apoptosis and/or autophagy besides restoring sensitivity to chemotherapeutic drugs [69]. A sexrelated loop would possibly involve $17 \beta$-estradiol (E2) that via $E R \alpha$ activates the miR-23 family and p53, in turn decreasing XIAP and inducing apoptosis [70]. Interestingly, miR-23a was reported to be differentially expressed by cells 
from male and female murine brains and XIAP was indicated as a mediator of sex-related responses after stroke [71]. Notably, also miR-23c, belonging to the same miR family, is localized on chromosome X.

An additional Armadillo family member was recently identified as localized on chromosome X (Xq21.33-q22.2). This tumor-suppressor gene, called ALEX1 (Arm protein lost in epithelial cancer), was downregulated along with progression in several different solid tumors originating from epithelial tissues and its restored expression resulted able to inhibit proliferation and induce apoptosis [72]. For this gene, a differential tissue-specific sex hormone regulation and a critical role of its chromosomal localization has recently been hypothesized [73].

Finally, numerous miRs have been reported to regulate apoptosis, autophagy, and necrosis, also connecting the crosstalk between these types of cell death. Here again, some of these miRs are located on chromosome X. Examples are miR-374a, which is involved in the autophagic process through the inhibition of autophagy-related 5 (ATG5) and Ultraviolet Radiation resistance associated (UVRAG) proteins, and miR-504, which acts on the expression of the key tumor suppressor p53 [74]. Of interest are the X-linked oncomir-221\&222, as among their direct targets include a relevant number of proapoptotic proteins such as phosphatase and tensin homolog (PTEN), p53 upregulated modulator of apoptosis (PUMA), apoptotic protease activating factor-1 (APAF1), and caspase 3 (CASP-3) [58, 75, 76], as well as the BCL2-like11 (Bc12L11)-Bax/Bak axis [77]. Additional targets of miR221\&222 are TP53INP1, PPP2R2A, and PGC-1a, recently described for their participation in cell death, either through apoptosis or autophagy [78, 79]. Last but not the least, beclin-1, a key player in autophagy, was demonstrated as a new target of miR-221 [80] (see Fig. 1).

\section{Conclusions}

Human genome studies evidenced the presence on the Xchromosome of an unexpectedly high number of genes and miRs. This apparently non-casual localization might suggest the existence of $\mathrm{X}$-linked functional circuitries, possibly contributing to sex-associated specificities, e.g., in immune responses. This fact, together with the presence of oncogenes apparently escaping XCI, could account at least in part for the sex disparity observed in several pathological settings. Furthermore, different possible mechanisms may account for the different sex-related expression levels of miRs, including Xlinked transcription factors or cross-regulation by other miRs localized on $\mathrm{X}$ chromosome [81, 82].

A special case of miR-dependent, sex-specific regulation of immune responses and cancer immunosurveillance discussed in this review is that of the PD-1/PD-L1 pathway, whose targeting with monoclonal antibodies (mAbs) has given really impressive therapeutic results [83, 84]. As mentioned, it has been observed that several miRs, either involved in the programmed cell-death processes or specifically targeting PD-L1, are localized on chromosome X. Therefore, an miR-based modulation of such pathway could be at the basis of many sex disparities observed between men and women in terms of stronger immunological responses and immunosurveillance [41, 44].

In this perspective, the need for further gender-specific research emerges in order to fill the gap between clinical data and our knowledge on the mechanisms underlying the detected gender disparity in the onset and response to therapy of different forms of cancer.

Finally, as very recently suggested by an Editorial appeared in Nature Medicine "the failure to assess the influence of sex chromosomes in studies of the genome doesn't necessarily boil down to a lack of tools: there is also a challenge of a lack of will. It takes a bit more effort to include sex chromosomes in certain genomic analyses, and so this step is sometimes skipped" [85]. We think the same stands for epigenetics, and time has come to deal with both issues in order to develop a real first-stage personalized approach to a number of lifethreatening diseases.

Acknowledgements Partially supported by the Italian Association for Cancer Research (IG 18526) to PM, (IG18815) to AC, and (IG11610) to LG and by Ministry of Health (RF-2011-02346986) to PM.

\section{Compliance with ethical standards}

Conflict of interest The authors declare that they have no conflict of interest.

Open Access This article is licensed under a Creative Commons Attribution-NonCommercial-NoDerivatives 4.0 International License, which permits any non-commercial use, sharing, distribution and reproduction in any medium or format, as long as you give appropriate credit to the original author(s) and the source, and provide a link to the Creative Commons license. You do not have permission under this license to share adapted material derived from this article or parts of it. The images or other third party material in this article are included in the article's Creative Commons license, unless indicated otherwise in a credit line to the material. If material is not included in the article's Creative Commons license and your intended use is not permitted by statutory regulation or exceeds the permitted use, you will need to obtain permission directly from the copyright holder. To view a copy of this license, visit http://creativecommons.org/licenses/by-nc-nd/4.0/.

\section{References}

1. Wizemann TM, Pardue M-L. Exploring the biological contributions to human health: does sex matter? Washington, DC: National Academy Press; 2001.

2. Ventura-Clapier R, Dworatzek E, Seeland U, Kararigas G, Francois Arnal J, Brunelleschi S, et al. Sex in basic research -concepts 
in the cardiovascular field. Cardiovasc Res. 2017;113:711-24. https://doi.org/10.1093/cvr/cvx066.

3. Mokdad AH, Dwyer-Lindgren L, Fitzmaurice C, Stubbs RW, Bertozzi-Villa A, Morozoff C, et al. Trends and patterns of disparities in cancer mortality among US Counties, 1980-2014. JAMA. 2017;317:388-406.

4. Gabriele L, Buoncervello M, Ascione B, Bellenghi M, Matarrese $\mathrm{P}$, Carè $\mathrm{A}$. The gender perspective in cancer research and therapy: novel insights and on-going hypotheses. Ann Ist Super Sanita. 2016;52:213-22.

5. Giampietri C, Petrungaro S, Filippini A, Ziparo E. Sex-related differences in death control of somatic cells. J Cell Mol Med. 2013;17:550-1.

6. Penaloza C, Estevez B, Orlanski S, Sikorska M, Walker R, Smith $\mathrm{C}$, et al. Sex of the cell dictates its response: differential gene expression and sensitivity to cell death inducing stress in male and female cells. FASEB J. 2009;23:1869-79.

7. Malorni W, Straface E, Matarrese P, Ascione B, Coinu R, Canu S, et al. Redox state and gender differences in vascular smooth muscle cells. FEBS Lett. 2008;582:635-42.

8. Maselli A, Matarrese P, Straface E, Canu S, Franconi F, Malorni W. Cell sex: a new look at cell fate studies. FASEB J. 2009;23:978-84.

9. Lista P, Straface E, Brunelleschi S, Franconi F, Malorni W. On the role of autophagy in human diseases: a gender perspective. J Cell Mol Med. 2011;15:1443-57.

10. Du L, Bayir H, Lai Y, Zhang X, Kochanek PM, Watkins SC, et al. Innate gender-based proclivity in response to cytotoxicity and programmed cell death pathway. J Biol Chem. 2004;279:38563-70.

11. Ortona E, Margutti P, Matarrese P, Franconi F, Malorni W. Redox state, cell death and autoimmune diseases: a gender perspective. Autoimmun Rev. 2008;7:579-84.

12. Matarrese P, Colasanti T, Ascione B, Margutti P, Franconi F, Alessandri C, et al. Gender disparity in susceptibility to oxidative stress and apoptosis induced by autoantibodies specific to RLIP76 in vascular cells. Antioxid Redox Signal. 2011;15: 2825-36.

13. Regitz-Zagrosek V. Gender and cardiovascular diseases: why we need gender medicine. Internist (Berl). 2017;58:336-43.

14. Clocchiatti A, Cora E, Zhang Y, Dotto GP. Sexual dimorphism in cancer. Nat Rev Cancer. 2016;16:330-9.

15. Carrel L, Willard HF. X-inactivationprofile reveals extensive variability in $\mathrm{X}$-linked gene expression in females. Nature. 2005;434:400-4.

16. Cotton AM, Lam L, Affleck JG, Wilson IM, Peñaherrera MS, McFadden DE, et al. Chromosome-wide DNA methylation analysis predicts human tissue-specific $\mathrm{X}$ inactivation. Hum Genet. 2011;130:187-201.

17. Cotton AM, Ge B, Light N, Adoue V, Pastinen T, Brown CJ. Analysis of expressed SNPs identifies variable extents of expression from the human inactive $\mathrm{X}$ chromosome. Genome Biol. 2013;14:R122.

18. Dunford A, Weinstock DM, Savova V, Schumacher SE, Cleary JP, Yoda A, et al. Tumor-suppressor genes that escape from Xinactivation contribute to cancer sex bias. Nat Genet. 2017;49:10-16.

19. Ostan R, Monti D, Gueresi P, Bussolotto M, Franceschi C, Baggio G. Gender, aging and longevity in humans: an update of an intriguing/neglected scenario paving the way to a gender-specific medicine. Clin Sci (Lond). 2016;130:1711-25.

20. Machiela MJ, Zhou W, Karlins E, Sampson JN, Freedman ND, Yang $\mathrm{Q}$, et al. Female chromosome $\mathrm{X}$ mosaicism is age-related and preferentially affects the inactivated $\mathrm{X}$ chromosome. Nat Commun. 2016;7:1843-11851.
21. Sandovici I, Naumova AK, Leppert M, Linares Y, Sapienza C. A longitudinal study of $\mathrm{X}$-inactivation ratio in human females. Hum Genet. 2004;115:387-92.

22. Knudsen GP, Pedersen J, Klingenberg O, Lygren I, Ørstavik KH. Increased skewing of $\mathrm{X}$ chromosome inactivation with age in both blood and buccal cells. Cytogenet Genome Res. 2007;116:24-28.

23. Bolduc V, Chagnon P, Provost S, Dubé MP, Belisle C, Gingras $\mathrm{M}$, et al. No evidence that skewing of $\mathrm{X}$ chromosome inactivation patterns is transmitted to offspring in humans. J Clin Invest. 2008;118:333-41.

24. Gentilini D, Castaldi D, Mari D, Monti D, Franceschi C, Di Blasio $\mathrm{AM}$, et al. Age-dependent skewing of $\mathrm{X}$ chromosome inactivation appears delayed in centenarians' offspring. Is there a role for allelic imbalance in healthy aging and longevity?. Aging Cell. 2012;11:277-83.

25. Cotter PD, May A, Fitzsimons EJ, Houston T, Woodcock BE, alSabah AI, et al. Late-onset X-linked sideroblastic anemia. Missense mutations in the erythroid delta-aminolevulinate synthase (ALAS2) gene in two pyridoxine-responsive patients initially diagnosed with acquired refractory anemia and ringed sideroblasts. J Clin Invest. 1995;96:2090-6.

26. Invernizzi P, Miozzo M, Battezzati PM, Bianchi I, Grati FR, Simon $\mathrm{G}$, et al. frequency of monosomy $\mathrm{X}$ in women with primary biliary cirrhosis. Lancet . 2004;363:533-4.

27. Brix TH, Knudsen GP, Kristiansen M, Kyvik KO, Orstavik KH, Hegedüs L. High frequency of skewed X-chromosome inactivation in females with autoimmune thyroid disease: a possible explanation for the female predisposition to thyroid autoimmunity. J Clin Endocrinol Metab. 2005;90:5949-53.

28. Kristiansen M, Knudsen GP, Maguire P, Margolin S, Pedersen J, Lindblom A, et al. High incidence of skewed X chromosome inactivation in young patients with familial non-BRCA1/BRCA2 breast cancer. J Med Genet. 2005;42:877-80.

29. Ozbalkan Z, Bagişlar S, Kiraz S, Akyerli CB, Ozer HT, Yavuz S, et al. Skewed $\mathrm{X}$ chromosome inactivation in blood cells of women with scleroderma. Arthritis Rheum. 2005;52:1564-70.

30. Medema RH, Burgering BM. The $X$ factor: skewing $X$ inactivation towards cancer. Cell. 2007;129:1253-4.

31. Hewagama A, Gorelik G, Patel D, Liyanarachchi P, McCune WJ, Somers E, et al. Overexpression of X-linked genes in T cells from women with lupus. J Autoimmun. 2013;41:60-71.

32. Rupaimoole R, Slack FJ. MicroRNA therapeutics: towards a new era for the management of cancer and other diseases. Nat Rev Drug Discov. 2017;16:203-22.

33. Pinheiro I, Dejager L, Libert C. X-chromosome-located microRNAs in immunity: might they explain male/female differences? The X chromosome-genomic context may affect X-located miRNAs and downstream signaling, thereby contributing to the enhanced immune response of females. Bioessays. 2011;33:791-802.

34. Selmi C, Brunetta E, Raimondo MG, Meroni PL. The X chromosome and the sex ratio of autoimmunity. Autoimmun Rev. 2012;11:A531-537.

35. Zhu Z, Liu W, Gotlieb V. The rapidly evolving therapies for advanced melanoma-Towards immunotherapy, molecular targeted therapy, and beyond. Crit Rev Oncol Hematol. 2016;99:91-99.

36. Dong Y, Sun Q, Zhang X. PD-1 and its ligands are important immune checkpoints in cancer. Oncotarget. 2017;8:2171-86.

37. Liu J, Morgan M, Hutchison K, Calhoun VD. A study of the influence of sex on genome wide methylation. PLoS ONE. 2010;5:e10028.

38. Singmann P, Shem-Tov D, Wahl S, Grallert H, Fiorito G, Shin $\mathrm{SY}$, et al. Characterization of whole-genome autosomal differences of DNA methylation between men and women. Epigenetics Chromatin. 2015;8:43-56. 
39. Evans TM, Simpson F, Parton RG, Wicking C. Characterization of Rab23, a negative regulator of sonic hedgehog signaling. Methods Enzymol. 2005;403:759-77.

40. Khor CC, Vannberg FO, Chapman SJ, Guo H, Wong SH, Walley $\mathrm{AJ}$, et al. CISH and susceptibility to infectious diseases. N Engl J Med. 2010;362:2092-101.

41. Klein SL, Flanagan KL. Sex differences in immune responses. Nat Rev Immunol. 2016;16:626-38.

42. Dinesh RK, Hahn BH, Singh RP. PD-1, gender, and auto---unity. Autoimmun Rev. 2010;9:583-7.

43. Osterweil N. Sex differences in T-cell profiles may drive anti-PDL1 responses. Intern Med News. 2016.

44. Zhou C, Tang J, Sun H, Zheng X, Li Z, Sun T, et al. PD-L1 expression as poor prognostic factor in patients with nonsquamous non-small cell lung cancer. Oncotarget. 2017;8:58457-68.

45. Tsai K, Daud AI. The role of anti-PD-1/PD-L1 agents in melanoma: progress to date. Drugs. 2015;75:563-75.

46. Cai H, Yuan Y, Hao YF, Guo TK, Wei X, Zhang YM. Plasma microRNAs serve as novel potential biomarkers for early detection of gastric cancer. Med Oncol. 2013;30:452-9.

47. Sharma A, Kumar M, Aich J, Hariharan M, Brahmachari SK, Agrawal A, et al. Posttranscriptional regulation of interleukin-10 expression by hsa-miR-106a. Proc Natl Acad Sci USA. 2009;106:5761-6.

48. Kroesen BJ, Teteloshvili N, Smigielska-Czepiel K, Brouwer E, Boots AM, van den Berg A, et al. Immuno-miRs: critical regulators of T-cell development, function and ageing. Immunology. 2015;144:1-10.

49. Streicher KL, Zhu W, Lehmann KP, Georgantas RW, Morehouse $\mathrm{CA}$, Brohawn $\mathrm{P}$, et al. A novel oncogenic role for the miRNA506-514 cluster in initiating melanocyte transformation and promoting melanoma growth. Oncogene. 2012;31:1558-70.

50. Stark MS, Bonazzi VF, Boyle GM, Palmer JM, Symmons J, Lanagan CM, et al. miR-514a regulates the tumour suppressor NF1 and modulates BRAFi sensitivity in melanoma. Oncotarget. 2015;6:17753-63.

51. Gong AY, Zhou R, Hu G, Li X, Splinter PL, O'Hara SP, et al. MicroRNA-513 regulates B7-H1 translation and is involved in IFN-gamma-induced B7-H1 expression in cholangiocytes. J Immunol. 2009;182:1325-33.

52. Chen J, Jiang CC, Jin L, Zhang XD. Regulation of PD-L1: a novel role of pro-survival signalling in cancer. Ann Oncol. 2016;27:409-16

53. Gantier MP. X-chromosome-encoded microRNA-19 and -18 are possible modulators of female immunity. Bioessays. 2013;35:671.

54. Khuu C, Utheim TP, Sehic A. The three paralogous microRNA clusters in development and disease, miR-17-92, miR-106a-363, and miR-106b-25. Scientifica (Cairo). 2016;2016:ID1379643.

55. Trenkmann M, Brock M, Gay RE, Michel BA, Gay S, Huber LC. Tumor necrosis factor $\alpha$-induced microRNA-18a activates rheumatoid arthritis synovial fibroblasts through a feedback loop in NF- $\mathrm{BB}$ signaling. Arthritis Rheum. 2013;65:916-27.

56. Cascio S, D'Andrea A, Ferla R, Surmacz E, Gulotta E, Amodeo V, et al. miR-20b modulates VEGF expression by targeting HIF-1 alpha and STAT3 in MCF-7 breast cancer cells. J Cell Physiol. 2010;224:242-9.

57. Xu S, Tao Z, Hai B, Liang H, Shi Y, Wang T, et al. miR-424(322) reverses chemoresistance via $\mathrm{T}$-cell immune response activation by blocking the PD-L1 immune checkpoint. Nat Commun. 2016;7:11406-19.

58. Garofalo M, Quintavalle C, Romano G, Croce CM, Condorelli G. miR221/222 in cancer: their role in tumor progression and response to therapy. Curr Mol Med. 2012;12:27-33.

59. Mitkov M, Joseph R, Copland J 3rd. Steroid hormone influence on melanomagenesis. Mol Cell Endocrinol. 2015;417:94-102.
60. Munoz J, Wheler J, Kurzrock R. Expression of estrogen and progesterone receptors across human malignancies: new therapeutic opportunities. Cancer Metastasis Rev. 2015;34: 547-61.

61. Pierdominici M, Maselli A, Locatelli SL, Ciarlo L, Careddu G, Patrizio $\mathrm{M}$, et al. Estrogen receptor $\beta$ ligation inhibits Hodgkin lymphoma growth by inducin autophagy. Oncotarget. 2017;8:8522-35.

62. Han SH, Kim HJ, Gwak JM, Kim M, Chung YR, Park SY. MicroRNA-222 expression as a predictive marker for tumor progression in hormone receptor-positive breast cancer. J Breast Cancer. 2017;20:35-44.

63. Di Leva G, Gasparini P, Piovan C, Ngankeu A, Garofalo M, Taccioli C, et al MicroRNA cluster 221-222 and estrogen receptor alpha interactions in breast cancer. $\mathrm{J}$ Natl Cancer Inst. 2010;102:706-21.

64. Evangelista AM, Deschamps AM, Liu D, Raghavachari N, Murphy E. miR-222 contributes to sex-dimorphic cardiac eNOS expression via ets-1. Physiol Genom. 2013;45:493-8.

65. Mattia G, Errico MC, Felicetti F, Petrini M, Bottero L, Tomasello $\mathrm{L}$, et al. Constitutive activation of the ETS-1-miR-222 circuitry in metastatic melanoma. Pigment Cell Melanoma Res. 2011;24:953-65.

66. Moulin M, Piquereau J, Mateo P, Fortin D, Rucker-Martin C, Gressette M, et al. Sexual dimorphism of doxorubicin-mediated cardiotoxicity: potential role of energy metabolism remodeling. Circ Heart Fail. 2015;8:98-108.

67. Ortona E, Matarrese P, Malorni W. Taking into account the gender issue in cell death studies. Cell Death Dis. 2014;5: e1121.

68. Straface E, Malorni W, Pietraforte D. Sex Differences in Redox Biology: A Mandatory New Point of View Approaching Human Inflammatory Diseases. Antioxid Redox Signal. 2017;26: 44-45.

69. Rathore R, McCallum JE, Varghese E, Florea AM, Büsselberg D. Overcoming chemotherapy drug resistance by targeting inhibitors of apoptosis proteins (IAPs). Apoptosis. 2017;22: 898-919.

70. Huang F-Y, Wong DK-H, Seto W-K, Lai C-L, Yuen M-F. Estradiol induces apoptosis via activation of miRNA-23a andp53: implication for gender difference in liver cancer development. Oncotarget. 2015;6:34941-52.

71. Siegel C, Li J, Liu F, Benashski SE, McCullough LD. miR-23a regulation of X-linked inhibitor of apoptosis (XIAP) contributes to sex differences in the response to cerebral ischemia. Proc Natl Acad Sci USA. 2011;108:11662-7.

72. Gao Y, Wu JY, Zeng F, Liu GL, Zhang HT, Yun H, Song FZ. ALEX1 regulates proliferation and apoptosis in breast cancer cells. Asian Pac J Cancer Prev. 2015;16:3293-9.

73. Zeng F, Liao K, Wu J, Gao Y, Li H, Fan J, et al. ALEX1 may be a novel biomarker for human cervical squamous cell carcinoma. Int J Clin Exp Pathol. 2015;8:9434-9.

74. Su Z, Yang Z, Xu Y, Chen Y, Yu Q. MicroRNAs in apoptosis, autophagy and necroptosis. Oncotarget. 2015;6:8474-90.

75. Zhou L, Jiang F, Chen X, Liu Z, Ouyang Y, Zhao W, et al. Downregulation of miR-221/222 by a microRNA sponge promotes apoptosis in oral squamous cell carcinoma cells through upregulation of PTEN. Oncol Lett. 2016;12:4419-26.

76. Errico MC, Felicetti F, Bottero L, Mattia G, Boe A, Felli N, et al. The abrogation of the HOXB7/PBX2 complex induces apoptosis in melanoma through the miR-221\&222-c-FOS pathway. Int $\mathbf{J}$ Cancer. 2013;133:879-92.

77. Zhao JJ, Chu ZB, Hu Y, Lin J, Wang Z, Jiang M, et al. Targeting the miR-221-222/PUMA/BAK/BAX pathway abrogates dexamethasone resistance in multiple myeloma. Cancer Res. 2015;75:4384-97. 
78. Chen Q, Zhou Y, Richards AM, Wang P. Up-regulation of miRNA-221 inhibits hypoxia/reoxygenation-induced autophagy through the DDIT4/mTORC1 and Tp53inp1/p62 pathways. Biochem Biophys Res Commun. 2016;474:168-74.

79. Xue $\mathrm{Y}$, Wei $\mathrm{Z}$, Ding $\mathrm{H}$, Wang $\mathrm{Q}$, Zhou $\mathrm{Z}$, Zheng $\mathrm{S}$, et al. MicroRNA-19b/221/222 induces endothelial cell dysfunction via suppression of PGC-1 $\alpha$ in the progression of atherosclerosis. Atherosclerosis. 2015;241:671-81.

80. Pradhan AK, Talukdar S, Bhoopathi P, Shen XN, Emdad L, Das SK, Sarkar D, Fisher PB. mda-7/IL-24 mediates cancer cellspecific death via regulation of miR-221 and the beclin-1 axis. Cancer Res. 2017;77:949-59.

81. Wijchers PJ, Festenstein RJ. Epigenetic regulation of autosomal gene expression by sex chromosomes. Trends Genet. 2011;27:132-40.

82. Felli N, Errico MC, Pedini F, Petrini M, Puglisi R, Bellenghi M, et al. AP2 $\alpha$ controls the dynamic balance between miR-126\& $126 *$ and miR-221\&222 during melanoma progression. Oncogene. 2016;35:3016-26.
83. Iwai Y, Hamanishi J, Chamoto K, Honjo T. Cancer immunotherapies targeting the PD-1 signaling pathway. J Biomed Sci. 2017;24:26-37.

84. Ni L, Dong C. New checkpoints in cancer immunotherapy. Immunol Rev. 2017;276:52-65.

85. Editorial. Accounting for sex in the genome. Nat Med. 2017;23:1243.

86. Castellano L, Giamas G, Jacob J, Coombes RC, Lucchesi W, Thiruchelvam $\mathrm{P}$, et al. The estrogen receptor-alpha-induced microRNA signature regulates itself and its transcriptional response. Proc Natl Acad Sci Usa. 2009;106:15732-7.

87. Sun T, Wang Q, Balk S, Brown M, Lee GS, Kantoff P. The role of microRNA-221 and microRNA-222 in androgenindependent prostate cancer cell lines. Cancer Res. 2009;69: 3356-63.

88. Wang YT, Tsai PC, Liao YC, Hsu CY, Juo SH. Circulating microRNAs have a sex-specific association with metabolic syndrome. J Biomed Sci. 2013;20:72-81. 